\title{
Retrospective Diagnosis of Ankylosing Spondylitis after Spinal Fractures: A Review of 3 Cases and Clinical Implication
}

\author{
Kamran Farooque Santanu Kar Burhan Salim Siamwala Vijay Sharma \\ Department of Orthopaedics, Jai Prakash Narayan Apex Trauma Centre, AllMS, New Delhi, \\ India
}

\section{Keywords}

Ankylosing spondylitis - Low-energy spinal trauma - Retrospective diagnosis of ankylosing spondylitis after trauma

\begin{abstract}
Ankylosing spondylitis (AS) is an underdiagnosed inflammatory condition in the initial stages of disease that can cause vertebral fractures in young adults after trivial trauma. Hence, lowenergy spinal fractures in young patients must be carefully evaluated to exclude AS as the treatment protocol (fixation levels, period of immobilization) may change drastically if AS is diagnosed. Here, we present cases of 3 patients who presented at emergency after low-velocity spinal trauma and diagnosed as AS during workup for fracture management. This cases series indicates underdiagnosis of AS in general population as well as importance of strong suspicion of AS in low-energy spinal fractures in the younger age-group.
\end{abstract}

(C) 2021 The Author(s).

Published by S. Karger AG, Basel

\section{Introduction}

Ankylosing spondylitis (AS) is a chronic multisystem inflammatory disorder that primarily affects axial skeleton of young adults, and if not treated appropriately in initial stages of disease, it may lead to diffuse syndesmophyte formation, loss of bone mineral density of vertebral column, and rigid kyphosis [1]. This rigid kyphotic structure exposes the spine to risks of transdiscal fractures and more rarely transcorporeal fractures which are often a result of minor trauma [2] with high propensity to compress neural structures due to already narrowed spinal canal [3] which often requires surgical management. The purpose 
of the case series is to describe the possibility of clinical debut of AS with a vertebral fracture and importance of meticulous clinico-radiological investigations to determine the pathology in low-energy spinal fractures in young adults.

\section{Case Report}

Case 1

A 32-year-old female housemaker by profession experienced a severe low back pain after a trivial fall from a chair. Neurologically, the patient was ASIA C (Thoracolumbar AO Spine Injury Score 12, CN3M2) at presentation without any bladder bowel involvement. There was no history of chronic low back pain or chronic intake of any medication. Radiographic evaluation was subsequently done which was suggestive of transdiscal fracture D11-D12 level along with bridging syndesmophytes with fish mouth vertebra (Fig. 1a). Subsequently, the patient was tested for HLA B 27 which was found to be positive. The patient was operated after 3 days of injury ( 2 days after presentation to our emergency) with posterolateral decompression and posterior long-segment instrumentation and interbody fusion with PEEK cage (Fig. 1b, c). The patient was started with medication for AS and mobilized with thoracolumbosacral orthosis (TLSO) brace after 4 days of surgery. The patient had no neurological deterioration and went back to normal life after 7 months after successful fracture union.

Case 2

A 48-year-old male farmer experienced severe low back pain in the thoracolumbar region. However, the patient did not have any neurological symptoms including bladder and bowel involvement (Thoracolumbar AO Spine Injury Score 8, CNOM2). He had complaints of stiffness of back for the past 10 years for which he has taken symptomatic treatment only. He was able to carry out his daily activities without any restriction of movements. There were no other injuries detected.StandardX-rays/CT spine showed typical bamboo spine appearance with fracture dislocation involving the transdiscal region of T12-L1 junction (Fig. 2a). Surgical management with posterior spinal fusion was done from T10-L3 using 12 screws and 2-rod construct, and posterior bone grafting (Fig. 2b, c) was performed after 5 days after injury ( 2 days after presentation to our emergency). Immediate post-operative period was uneventful. Later, the patient was mobilized with TLSO brace. The patient became a community ambulator after 8 months of surgery.

Case 3

This 40-year-old male patient, a software engineer by profession, presented to emergency after severe low back pain immediately after a fall from standing height during walking. The patient admitted that previously he had mild low back pain after prolonged sitting since the last 2 years, but activities of daily life was not hampered. There was complete neurological deficit ASIA A (Thoracolumbar AO Spine Injury Score 7, A3N4M2) with bladder and bowel involvement. Subsequent radiograph delineated a burst fracture at D10 level (A0 type A3) with D9-D10 bridging syndesmophytes with marked decrease of disc spaces along the spinal column. The radiological findings were not very typical of AS (Fig. 3a). We performed an HLA-B27 which came out to be positive. The patient was operated with complete corpectomy with posterolateral decompression with longsegment fixation (Fig. 3b, c) (from D8-L2) with interbody cage fixation (3 days after presentation). The patient was started with medication for AS and discharged with mobilization with TLSO brace. Fracture union was evident after 4 months, and the patient was

\section{Karger's}


Case Reports in Orthopedic Research

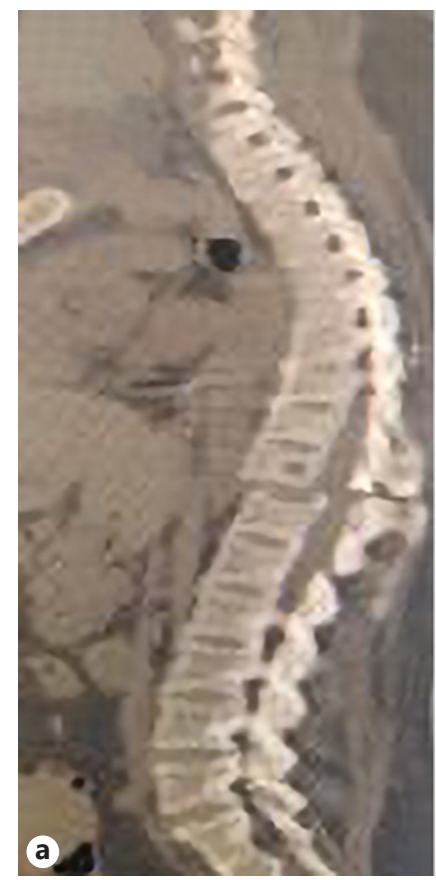

\begin{tabular}{l|l}
\hline Case Rep Orthop Res 2021:4:173-179 \\
\hline DOI: 10.1159/000516132 & $\begin{array}{l}\text { ○ 2021 The Author(s). Published by S. Karger AG, Basel } \\
\text { www.karger.com/cio }\end{array}$ \\
\hline
\end{tabular}

Farooque et al.: Retrospective Diagnosis of AS after Spinal Fractures: Case Series

Fig. 1. Preoperative (a) CT scan and post-operative radiograph (b, c).
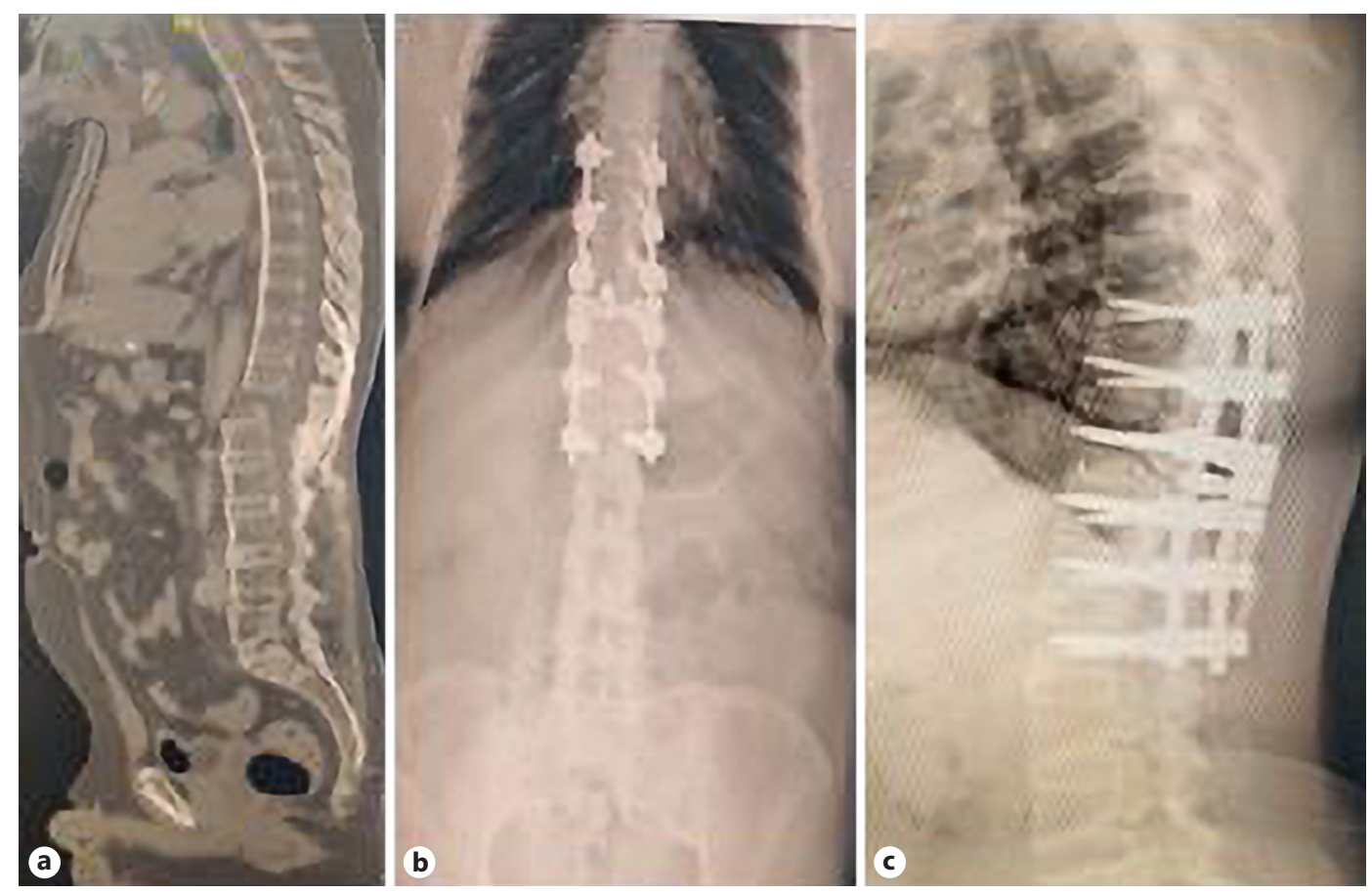

Fig. 2. Preoperative (a) CT showing characteristic fused spinal column showing transdiscal fracture and post-operative radiograph $(\mathbf{b}, \mathbf{c})$.

pain free; the patient was neurologically ASIA B after 11 months. This patient was followed up for 3 years and there was no neurological improvement. Table 1 shows the summary of cases with final outcome after surgery.

Karger' 
Case Reports in Orthopedic Research

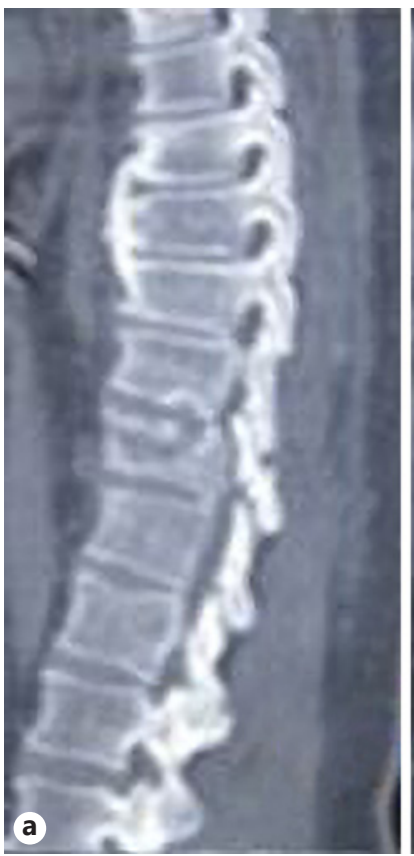

Fig. 3. Preoperative (a) CT scan showing anterior bridging syndesmophytes with burst fracture and postoperative radiograph $(\mathbf{b}, \mathbf{c})$.

\section{Discussion}

AS is characterized by chronic inflammation and enthesitis, mainly involving axial skeleton leading to loss of resilience and elasticity of spinal column. Additionally, this rigid spinal column becomes osteoporotic due to demineralization [4] by enhanced bone resorption and reduced bone deposition at inflammation sites which are mediated by cytokines [5]. We noted marked osteoporosis in radiographs in relatively younger patients (case 1 and 3), but marked syndesmophyte formation in advanced disease can mask the osteoporosis radiographically [6] (case 1 and 2).

The importance of a meticulous history in emergency setting cannot be overemphasized. In patients who are already diagnosed with AS and visit emergency after trivial fall, the management is relatively straight forward. But in our case series, no patient was previously diagnosed with AS. The severity of pain precludes a complete examination of spine. On clinical examination, only 1 case (case 2) had marked kyphosis and long standing history of low back pain which raised the suspicion of a pathological arthritis and stiff spinal column. But in the 2 other cases (case 1 and 3), no or relatively short duration history of low back pain did not raise suspicion of any pathological process initially. The severe neurodeficit (case 3) after a minor trauma led the emergency team to sought alternate diagnosis of pathological vertebral fracture. The radiological findings may not be classical in young patients (case 3), but diagnosis of AS should be kept in mind and the patient should be investigated for the same.

There is significant difference in management of vertebral fractures in AS and non-AS cases. The most frequent type of vertebral fractures in AS patients are AO B3 type, M2 subtype (but other types have also been reported) which is invariably an unstable spinal injury that requires urgent surgical intervention [7]. The osteoporotic, stiff spinal column became mechanically unstable after minor trauma (case 1 and 3) which have a higher propensity for spinal cord injury, nerve root involvement, intramedullary oedema, and epidural haematoma 
Case Reports in Orthopedic Research
Case Rep Orthop Res 2021;4:173-179 DOI: $10.1159 / 000516132$ (c) 2021 The Author(s). Published by S. Karger AG, Basel Farooque et al.: Retrospective Diagnosis of AS after Spinal Fractures: Case Series

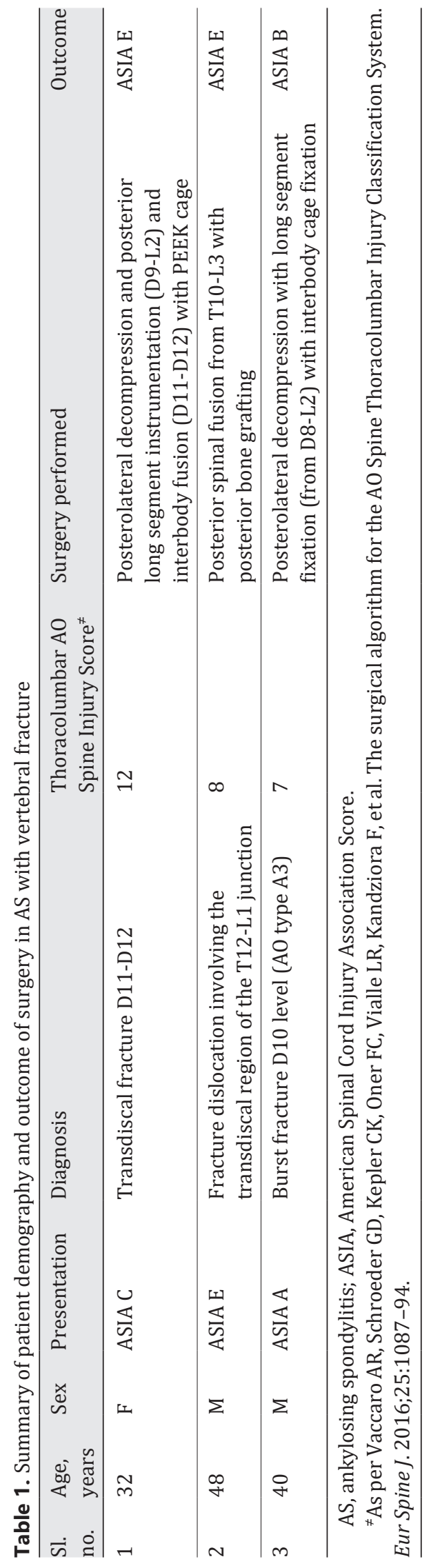

\section{Karger's}


in AS patients in comparison to non-AS spinal trauma patients [3]. Non-operative management not only exposes the patient to high risk of displacement of the fracture and neurologic deterioration but renders the patient susceptible to systemic complications due to prolonged bed rest. The altered biomechanics of spinal column due to stiffness on the background of ongoing inflammation can be a harbinger of the so-called "traumatic Anderson lesion" at the discovertebral junction that signifies pseudoarthrosis in conservatively managed vertebral fractures in AS. Hence, operative stabilization with a long-segment fixation must be accomplished to have a better outcome in AS patients with vertebral fracture in comparison to non-AS cases. There is also higher predisposition to multilevel spinal injury in AS than non-AS cases which must be meticulously excluded by screening with whole-spine CT scan before embarking on the operative procedure [8].

The vertebral fractures occur more frequently in cases of AS with peripheral involvement than in cases with isolated axial involvement [9]. But in our series, we noted spinal fractures without any peripheral involvement. Due to sparing of large joints (like hip) which allowed the patients to maintain their activities of daily life, they did not seek medical attention leading to non-detection of the clinical entity in the early stage of the disease. Timely surgical fixation can improve neurological function and reduce the incidence of overall complications [10] and significantly improve the survival rate [11]. Theoretically, there may be chances of better decompression of spinal column when approached from the anterior side, but this often aggravates the surgical trauma leading to high risk of complications [12]. Practically, posterior approach is most commonly used [10] which also has the added advantage of adding more stability to spinal column due to placement of hardware on the tensile side [13]. We believe that meticulous posterior decompression is sufficient to achieve a favourable outcome. We performed posterolateral decompression, $360^{\circ}$ fusion, and posterior instrumentation -3 vertebra above and below of the fractured level for a rigid and stable construct. After a minimum 3 years of follow-up, we did not find any implant failure in any of the 3 patients.

It is not usual to have clinical debut of AS with a fracture. The failure to diagnose the disease by the primary attending physician is multifactorial. There may be minimal functional deficit without need of frequent medication for pain relief (case 1), adaptation with deformity and functional deficit (case 2), patient tolerance to pain, lack of classical radiological signs in initial radiographs, lack of patient knowledge and non-adherence to follow-up, and combination of these factors (case 3). This strengthens the fact that delay of several years from clinical symptoms to diagnosis is not unusual to diagnose AS [14].

We used Assessment of Ankylosing Spondylitis (ASAS) classification criteria to diagnose AS retrospectively as there is limitation of modified New York criteria to diagnose the condition early and a wider term "axial spondyloarthropathy" is being used currently instead of "ankylosing spondylitis" [15]. After definite diagnosis, medical management for ankylosing spondylitis was started in three patients mentioned in our study.

\section{Conclusion}

Clinical debut of AS with vertebral fractures is possible. Young patients with low-energy vertebral fractures should be carefully evaluated to diagnose the clinical entity before undertaking surgical intervention.

\section{Karger'}


Case Reports in Orthopedic Research

\begin{tabular}{l|l}
\hline Case Rep Orthop Res 2021:4:173-179 \\
\hline DOI: 10.1159/000516132 & $\begin{array}{l}\text { ○ 2021 The Author(s). Published by S. Karger AG, Basel } \\
\text { www.karger.com/cio }\end{array}$ \\
\hline
\end{tabular}

Farooque et al.: Retrospective Diagnosis of AS after Spinal Fractures: Case Series

\section{Statement of Ethics}

Written informed consent was obtained from the patients for publication of this case report and written permission was also obtained for possible printing and circulation of the accompanying radiological images solely for educational and academic purposes.

\section{Conflict of Interest Statement}

The authors declare no conflicts of interest for publishing and preparing the manuscript.

\section{Funding Sources}

The authors did not receive any funding.

\section{Author Contributions}

Prof. K.F. and Prof. V.S. operated the cases and guided in manuscript preparation. S.K. and B.S.S. assisted in surgery, prepared the manuscript, and followed up the cases.

\section{References}

1 Ghozlani I, Ghazi M, Nouijai A, Mounach A, Rezqi A, Achemlal L, et al. Prevalence and risk factors of osteoporosis and vertebral fractures in patients with ankylosing spondylitis. Bone. 2009 May;44(5):772-6.

2 De Peretti F, Sane JC, Dran G, Razafindratsiva C, Argenson C. [Ankylosed spine fractures with spondylitis or diffuse idiopathic skeletal hyperostosis: diagnosis and complications]. Rev Chir Orthop Reparatrice Appar Mot. 2004 Sep;90(5):456-65.

3 Jacobs WB, Fehlings MG. Ankylosing spondylitis and spinal cord injury: origin, incidence, management, and avoidance. Neurosurg Focus. 2008;24(1):E12.

4 Will R, Palmer R, Bhalla AK, Ring F, Calin A. Osteoporosis in early ankylosing spondylitis: a primary pathological event? Lancet. 1989 Dec 23-30;2(8678-9):1483-5.

5 Raisz LG. Local and systemic factors in the pathogenesis of osteoporosis. N Engl J Med. 1988;318(13):818-28.

6 Donnelly S, Doyle DV, Denton A, Rolfe I, Mccloskey EV, Spector TD. Bone mineral density and vertebral compression fracture rates in ankylosing spondylitis. Ann Rheum Dis. 1994 Mar 1;53(2):117-21.

7 Reinhold M, Knop C, Kneitz C, Disch A. Spine fractures in ankylosing diseases: recommendations of the spine section of the German Society for Orthopaedics and Trauma (DGOU). Global Spine J. 2018;8(2 Suppl):56S-68S.

8 Caron T, Bransford R, Nguyen Q, Agel J, Chapman J, Bellabarba C. Spine fractures in patients with ankylosing spinal disorders. Spine. 1976;35(11):E458-64. 2010

9 Fox MW, Onofrio BM, Kilgore JE. Neurological complications of ankylosing spondylitis. J Neurosurg. 1993; 78(6):871-8.

10 Westerveld LA, Verlaan JJ, Oner FC. Spinal fractures in patients with ankylosing spinal disorders: a systematic review of the literature on treatment, neurological status and complications. Eur Spine J. 2009 Feb;18(2): 145-56.

11 Robinson Y, Willander J, Olerud C. Surgical stabilization improves survival of spinal fractures related to ankylosing spondylitis. Spine. 2015 Nov;40(21):1697-702.

12 Whang PG, Goldberg G, Lawrence JP, Hong J, Harrop JS, Anderson DG, et al. The management of spinal injuries in patients with ankylosing spondylitis or diffuse idiopathic skeletal hyperostosis: a comparison of treatment methods and clinical outcomes. J Spinal Disord Tech. 2009 Apr;22(2):77-85.

13 Liu R, Sun L, Li CH, Zhai JY, Liu XY. [Cause analysis of spinal surgery in ankylosing spondylitis]. Beijing Da Xue Xue Bao Yi Xue Ban. 2017 Oct 18;49(5):835-9. Chinese. PMID: 29045965.

14 Fallahi S, Jamshidi AR. Diagnostic delay in ankylosing spondylitis: related factors and prognostic outcomes. Arch Rheumatol. 2016 Mar;31(1):24-30.

15 Braun J, van den Berg R, Baraliakos X, Boehm H, Burgos-Vargas R, Collantes-Estevez E, et al. 2010 update of the ASAS/EULAR recommendations for the management of ankylosing spondylitis. Ann Rheum Dis. 2011 Jun; $70(6): 896-904$. 